\title{
XLIX. Report made to the French institute on a memoir of M. Delaroche on the air-bladder of fishes
}

\section{G. Cuvier}

To cite this article: G. Cuvier (1810) XLIX. Report made to the French institute on a memoir of M. Delaroche on the air-bladder of fishes, Philosophical Magazine Series 1, 35:144, 291-302, DOI: $10.1080 / 14786441008563084$

To link to this article: http://dx.doi.org/10.1080/14786441008563084

曲 Published online: 18 May 2009.

Submit your article to this journal $\pi$

ЏII Article views: 2

Q View related articles $₫$ 


\section{$[291]$}

XIX. Report made to the French Institute on a Memuar of M. Delanoche on the Air-bladder of Fishes. BY G. Cuvier.

$\mathrm{T}$ He mathematical and physical classs instructed Messrs. Lacepede, Vauquelin, and myself, to render an account of a memoir by $M$. Francis Delaroche on the air-bladder of fishes.

As several naturalists have been of late employed in directing their attention to the organ which is the object of this memoir, and to its functions, we do not think it will be improper to preface our report by a historical view of what has been said on the subject; a recapitulation for which M. Delarocke himself has firnished us with arple materials.

The air-vessel of fishes is too remarkable, it strikes the eye too forcibly on the first opening of the animal, and differs too much from every other organ, not to awaken the attention of naturalists; but, like most objects in comparative anatomy, it has long produced mote conjectures and hypotheses than exact observations and experimental researches.

Rondelet * confined himself to the observation, that it existed more constantly in fresh than in salt-water fishes; and that it probably serves to assist them in swimming.

Marcus Aurelius Severinus risks an opinion that the air of this vessel was produced along with the animal; which proves that he had never perceived any communication with it outwards.

Gauthier Neetham (in 1668) was the first who entered into more detailed inquiries, and inserted them in a book, where no one wauld expect to find them; namely, De formato fatu + . Adopting the general idea of the utility of this bladder for swimming, he explained how flat fish are enabled to do without it; he described the two tunics of this organ, as well as the varieties of its form, and the origin of the canal of communication. He shows that the vessels are more abundant than are requisite for its own nutrition; that it is probable that some organic function is exercised by them, and that the blood contained in them has some eonnexion with the air: but judging that it would be difficult for the air to penetrate into it from withbut, in certain fishes; through substances which fill the

* Hist. Pisc. 1554;pp. 26 and 73.

+ Billoglh. de Manget, ii. pp. 715 and 714.

T 2

stomach 
stomach, he conjecturer that this fluid is secreted there, and that it proceeds from thence into the stomach, where it assists in the process of digestion : he even points out the red bodies which operate this secretion in the snake.

Borelli explained in detail, in 1676 , the method in which the bladder is used in swimming. He observed that fishes, whose air-bladders burgt, remain at the bottom of the water, as well as most of those which are maturally deprived of it; and concludes that it is intended to render the body of the fish sufficiently light to be in equilibrium with the water: he added, that by compressing the bladder, or by abandoning the air which it contains to its elasticity, the fish can augment or diminish its total specific gravity, and assist it in its ascent or descent. He supposed, that the canal which establishes in certain fishes a communication between the air-bladder and the stomach, must be a method of varying or renewing the quantity of air *.

To conclude : he tras neither described the varieties of the structure of the bladder, nor determined in: what fishes it exists, and those in which it is wanting.

Redi resumes the observations of Neetham. He added some details on those fishes which have no air-bladder, and on the red bodies in the interior of several of these organs. He also stated, that he had in vain sought for the eanal of communication in certain sea-fishes; but he thought that it was his fault, and this opinion of the geirerality of the existence of the canal has even reigned to the present time among some others. These remarks of Redi are still to be found in a book entitled, Otservotions sur les Animaux vivans contenus dans les Animaux vivans. Florence, 1684.

Ray and Willoughby, without making fresh inquiries, and without deciding on the manner in which the air is introduced into the bladder, disputed the idea of this air being used in digestion, and reduced the bladder to its employment in swimming, according to the ideas of Borelli. They insisted on the muscles peculiar to certain vessels, and mistook for them the red bedies in the interior of some others $t$.

The same opinion on the use of the bladder was supported by Preston $t$, by Perrault $\$$, and by Petit $\|$ : Perrault made the important observation, that there are fishes

* De Mot. Animal. cap. 25. De Natalu.

+ Willoughby, Hist. Pisc. 1686, pp- 12 et seq.

7 Phil. Trans. xix. p. 499.

Mécanique des Animaux, part: lh ch. ii. volii-p. 883 of his works, 1721. DEem, de l'Acad 1739; 
without any canal, and that it is in the latter that the red bodies are found, which are intended for the separation of the air. Ho added, that in those which have a canal, the air dines nol issue from the bladder, although it be compressed; a remark too much generalized.

Petit, on the contrary, thought he had discovered in the canal of the carp, valvuli which admit of the air escaping, but not of retarning.

Notwithstanding the observation of Perrault, Artedi still ascribed to all bladders a canal destined, according to him, for the introduction of air: but, with the exception of Borelli's*, there is no opinion given respectung their use.

It is the same case with Gouan, Bloch, and a variety of other authors, who add nothing in other respects to the details previously acquired.

But, actmitting in its fullest extent this chief employment of the air-bladder, we might still suppose it to have accessory uses, and in particular we must defer giving any opinion as to the origin of the air which it contains.

This was the conduct pursued by Vicq d'Azyr in 1773 t. He imagined that the air originated in the stomach, from whence it entered, charged with nutritive particles, into the air-bladder, in order to be absorbed by the vascular system. He was follow $\mathrm{d}$ by Broussonnet in this idea $\S$ under some modifications.

Erxleben entertained the same idea respecling the propagation of the air; but as to its uses be followed the common opinion \#.

These three anatomists seem to have been ignorant that the communication between the stomach and the air-bladder is frequently wanting.

This is strongly insisted upon by Kohlreuter 1 in an anatomical description of the lotus. After having ascertained the defect in the canal, and that a number of other fishes are also without it, and after having described the organization of the red bodies, he maintained that the air is separated from the blood in the bladder. He thought his system was new, not having read the writings of Perrault and Needbam.

Leske adopted the opinion of Kohlseuter**.

- Partes Pisr. 1738 , p. 36.

+ Hist. des Poissnnc, 1770 , p. 81

$\$$ Némotres presentes, tome vii.; and his Physiological Works, tome ii. p.20s.

S Var. Posit. circ. Respir. sect. v.

1776 , in a memoir on the subject; and also in his Natural History, edit, 5797 , p. 979 .

Nov. Comm. Petropolit. tome xix. 1775.

* Hist. NGt. 1724, p. 390. 
Monro, who in his work on fishes ought to have thrown a great deal of light on this subject, has added but little to what was known before on this subject. He made the same distinction with Perrault between bladders with secretory red budies which have no canal, and those which have a canal and want these bodies; but he does not mention any French anatomist; perhaps because he had never read any of their works on the subject.

He remarked that the genus anguilla formed an excep: tion to the rule, from having the canal and red bodies, With respect to the other parts of the question, he did not decide upon the use of the bladder; and merely inquired, if fishes could not, in swallowing, distinguish the bubbles of air from the mass of water, and make them pass in preference into this organ.

M. Fischer, now professor at Moscow, published in 1795 , at Leipsic, a particnlar dissertation on this subject; in which after baving given an extract of the writings of his predecessors, and having communicated his own observations on the carp and the tench, he hazarded the opinion, that the air-bladder, independent of its uses for motion, is also a supplementary organ of respiration, destined to absorb the oxygen from the atmospheric air contained in water, as the gills are destined, according to him, to absorb the oxygen of the water itself, by decomposing it.

M. de Lacepede supposes, that certain fishes may at least fill their bladder with the gases resulting from the decompositions which their respiration occasions. He thought that it was frequently hydrogen with which it was filled', and he mentioned tenches in which he had collected precisely this kind of gas.

Finally, M. Duvernoy, editor of that part of Cuvier's comparative anatomy which has for its object the airbladder of fishes, adopted, in common with M. Cuvier, the opinion of Needham and Kohlrenter, that the air is produced in the bladder by secretion. He also described some of the organs of this secretion in fishes not before observed; but, from too much precipitation, he forgot to advance the principal argument, founded on the absence of all canal of communication in many species. He concludes, from the absence of the vessel itself in fishes belonging indiscriminately to all descriptions of families, and even to genera the other species of which are furnished with it, that its functions cannot be very essential to life. By comparing its proportional volume with the nature of the movements of every fish, and by examining the supplementary means 
granted to those who have it not, and the various effects of those means, he arrives at the conclusion that it is essentially an organ connected with loci-motion.

He expresses his astonishment at the discordance between the analysis hitherto given of the air containt $d$ in this bladder; some, iike W. Fourcroy, having found hardly any thing but azote; whers, like $M$. Configliati, having found so much as 40.0 of oxygen; while others, like Mr. Broadbelt, found alc quantity variable in the same kind of fish according to circumstances. M. Duvernoy concludes with suggestug that chemists should inguire into the causes and limits of these variations; a precise knowleuge of which couls alone decide a great number of the questions in dispute.

Messrs. Geoffioy and Vauquelin on one hand, and M. Biot on the other, have recently made a great part of the experiments which were pointed our as reguisite by M. Duvernoy.

M Biot, in his first voyage to Ivica, examined the air in the bladder of several fisbes of the Mediterranean, and found that it varicd from pure azote up to 870 of oxygen, with very little carbonic acid, and without any hydrogen, and What in general the oxygen is the more abundant, in comparison to the azote, as the fisb comes from a greater depth, although the water at these great depths does nut contain a purer air than that which is at the saifface.

He also macie the curions observation, that in fishes suddenly drawn from a great depth, the air-blakder ceasing to be compressed by the cnormous column of water which bore upon it, is dilated so suddenly that it tears the intestines, and is cjected from the wouth. As to the origin of the air contained in it, he scems to think it has been secreted.

The expcriments of Messrs. Vanquelin and Geoffroy, pubfished by M. Biot, confirm his own on the subject, so far as the fishes on which they were male, living in nur fresh waters and at very small depths, gave but very linle uxygen. They agree also with other more ancient expriments of M. Fourcroy, who bad found nothing in the blatder of the carn but azote almost pripe, and with the analysis made, by $M$. Humboldt of the air in the bladder of the gymnotus electricus, which consisted ot 96.0 of azote and 40.0 of oxvgen.

Such was the whole of our knowledge of the air-bladder of fishes when M. Delaroche read his memoir to the InstiHute. But in ordeg to complute the series of facts which are $\mathrm{T}+$ necessary 
necessary to guide us in forming an opinion of his theory, we think it right to say a few words upon two memoirs published since.

One of these, by M. Geoffroy, refers to an earlier memoir, in which he develops, anatomically, the means by which the fish compresses or relaxes its bladder, in order to descend or ascend. Indeed, he says at the same time, in the introduction of his memoir, that the bladder is by no means an organ of motion by itself; but this is because be thought that those who regarded it as such, suppose that it is dilated by the increase of the air which it contains, and vice versá, an opinion which no person seems to have entertained; for it is always by the action of the muscles that it has been made to be compressed or dilated: on this subject, therefore, M. Geoffroy is really of the opinion of Borelli, which is the commonly received idea.

The other memoir to which we have alluded, is by Messrs. Humboldt and Provençal, and has for its chief object the respiration of fishes; but these authors have naturally been led to examine the air in the swimming-bladder.

They operated upon river fishes, and found the air variable in composition from $99^{\circ} 0$ of azote to 87.0 . They have observed as much as 5.0 of carbonic acid. They made some tench respire hydrogen, and yet their air-bladders when examined exhibited none; by keeping them in oxygen, however, the proportion of the oxygen in the bladder was somewhat increased. On removing the bladder from them, they were not prevented from producing by their respiration the ordinary effects upon the atmosphere; they were even able to raise themselves in the water, although they generally remained at the bottom of the vessel.

Thus, in the numerous works we have analysed, almost every possible hypothesis has been proposed, attacked, of defended, and examples have been given of almost all the combinations of organization that could be devised. M. Delaroche had only therefore to examine these organizations a little further, in order to reduce them to general rules, and to weigh over again the arguments advanced for or against every hypothesis.

Let us see how he has acquittcd himself of this task.-

His residence at Ivica, Formentero, and on the coast of Spain, with Messrs. Biot and Arrago, having furnished him with oppurtunities of examining a great number of Mediterranean fishes not to be seen any where else, and their air-bladders having chiefly occupied his attention, be continued his inquiries after his return, on our common 
fresh-and salt-water fishes : hence he has furnished upwarda of fifty particular descriptions of the air-bladders of as many species of fish, several of which have not hitherto been described. These descriptions, added to those which former authors had given of some species which M. Delaroche could not find, form the materials of bis present memoir; and he has placed his own at the end of the work, as so many proofs of the general propositions which he lays down.

In the body of the memoir he treats successively of the anatomical structure of the air-bladder, of the nature of the sources of the air which it contains, and of the functions which it exercises.

He speaks in the first place of its existence, and gives a list of those fishes which have it, and of those in which it is wanting. The results of this list, which adds several species to those which had already been adduced with respect to this subject, are nearly the same which had been already drawn; namely, that the existence or non-existence of the bladder does not correspond with the other affinities of organization which connect fishes with each other.

He afterwards speaks of the various situations of the bladder, of its variation in size, and in the configuration of its tunics, (an article in which he compares the internal membrane to the serous memhranes); and finally, of the particular muscles which it has in several fishes; and he gives a more detailed description of these muscles than is to be found in the comparative anatomy of $\mathbf{M}$. Cuvier.

What he says on the subject of the canal of communication also presents a great number of novelties. On this head he has made some very acute remarks, and has ascertained that this canal is wanting in the greater part of sea fishes. He did not find it in any of the jugular or thoracic classes, which compose nearly three-fourths of the total species of fishes with which we are acquainted. The lectures on comparative anatomy had assigned this canal to the uranoscope, which is a jugular; but according to M. Delaroche, the authors of this work have made new inquiries, and found that they were mistaken.

M. Delaroche has studied in a particular manner the red bodies with which certain bladders are furnished. He found them, like Perrault and Monro, in all those wbich want the canal of communication, and in the anguilla genus although furnished with this canal.

Our author gives a very detailed description of these tondies, in the gadi, 'the trigli, the perches, some labri and sholocentres, as well as in the atherina rhepsetus, the blennru 
physis, the orphius or esox belonus, and lastly in the eel and the conger.

We have verified that part of the descriptions which refers to the species with which we are familiar, or could procure, and have found them genterally correct.

It appears to us, however, that M. Delaroche grants too great a homogeneity to the inner texture of these bodies. One of our number, who, along with M. Duvernoy, recently made some inquiries in order to verify this point of anatomy, found these bodies in the larger fishes formed of lobes flattened like ribands, placed almost parallel on each other, very distinct from one another by clearly marked intervals, and proceeding obliquely in various directions from the proper membrane to the internal membrane of the bladder.

The distribution given by $M$. Delaroche of the vessels which issue from the red bodies of the eel, and from those which return to it, has also been verified, and found correct; but he passes rather too hastily over the red body itself, which is also divided into flakes, separated by intervals, which are frequently found filled with blood.

In short, Messrs. Cuvier and Duvernoy think they have found strongly marked relations in the red bodies of fishes with the cavernous bodies; but their inquiries posterior to the memoir of M. Delaroche, are only brought forward here that the Institute may not be ignorant of what has been done on this interesting subject. A full account of their experiments will shortly appear.

The author of the present Memoir speaks only from the lectures in comparative anatomy as to certain branching air-bladders, entirely peculiar to one species of fish. M. Cuvier, who had described them when on the sea coast; where he had no books from which to determine the spejies of the fish, thought it was the perca labrax; but other naturalists, besides himself, have since sought for it in vain in the fish so called in the systems of ichthyology. By unexpected good fortune, the true fish which was the subject of observation was brought to Paris some time ago, and proved to belong to the rare species denominated by M. Lacepede cheilodiptera, or sea eaglet, but which ought to be placed among the centropommes, beside the labrax.

The bladder of this fish, unique of its kind, will be presented to the Institute along with a description by $\mathrm{M}$. Duvernoy, and which will be more minute than any hitherto given under less advantageous circumstances.

In his analysis of the air contained in the bladder, M.

Delaroche 
Delaroche confirms in general the experiments of M. Biot; adding, that besides the various degrees of depth at which fishes live, there are other causes which concur to vary the proportions of the gases in their air-bladders. Thus, of two fishes caught on the same spot, one has given $50 \cdot 0$ and the other scarcely 40 of oxygen. M. Delaroche also rectifies the idea that M. Biot had given of the eruption of the bladder from the mouth, in fishes drawn up suddenly from great depths, when be says that a rupture of the bladder then takes place, and that it is the air which forces up the stomach to the mouth. As to the source of this air, our author (like Needham, Perrault, Monro, Kcohlreuter, Duvernoy and Cuvier, thinks it is produced in the interior of the bladder by a secretion of an unkniown nature, of which the red bodies seem to be the organs in such fishes as have these bodies.

It is unnecesssary to ask for a proof of this opinion in fishes which have no exterior canal, for in them it is demonstrated by itself. We might also fairly extend it to those which have a canal and red bodies, like the eel.

But in those which want the red bodies, as we must admit a new kind of exhalation, the analogy no longer takes place completely; and perhaps many persons would be equally willing to have recourse to the aerial canal, in so much as it always exists in this description of fishes. As fishes of the same family frequently have the air-bladder, and others want it, it is probable that its functions may be supplied by different means.

M. Delaroche, without considering that question as at all decided, nevertheless supports the argument of ana!ogy, from the difficulty which any given gas would have in many species, in penetrating into the bladder by the canal; from the still greater difficulty which it would have of arriving pure, particularly when it was requisite for it to nass through the substances contained in the stomach; and, lastly, from the difficulty of knowing, from whence, or by what mechanism, the fish could procure it from nature, in oveder to introduce it into its bladder at great depths, where it is so frequently and so long retained.

The habit in which physiologists ars of seeing matters of every kind come nut of the blood by secruions, renders them on the contrary very easy as to this k.ud of production; and in fact there is no' real difficulty on the subject, since azote and oxygen, which compose the air in the bladder, exist abundantly in the blood.

But it may be asked; If the gas be exhaled or separated from 
from the blood, wherefore does it vary so much when the greater part of the other secretions are so constant in their nature? Above all, how can the animal body, so greedy of oxygen in general, exhale it so precisely at depths where it has the fewest methods of getting it from the external medium ? M. Delaroche, who puts these questions, admits that it is difficult to answer them satisfactorily.

He afterwards proceeds to the uses of the air-bladder.

From its absence in many fishes taken indiscriminately from all classes, he concludes, with the authors of the comparative anatomy, that it cannot hold an important place in the vital functions; and this makes him reject all necessary connexion between the air-bladder and respiration.

He would have even been inclined to conclude, from its solute stoppage in the greater number of fishes that are furnished with it, that it could not in general be employed in the absorption of any useful matter, in the excretion of any injurious substance, nor even in the production of a substance to be employed in some other part of the body; but that it is solely by itself as the air-vessel, and in its quality of considerable capacity, flled with a light elastic substance that it may be useful to the fish.

Now in this respect it can only have a mechanical use, either with respect to its station or movement.

M. Delaroche in the first place ascertains its use in the station, and admits that it serves to render the whole fish specifically lighter, and to place it in equilibrium with the water in which it is suspended.

This is one part of the most generally received opinion; but it is clear that the necessity of the bladder for this sole purpose is any thing but demonstrated. Nature would rather have made all fishes of the same gravity as the water, as she has done with those fisbes that have no bladders: thus, the common opinion is also composed of two other integrant parts equally necessary with the former. The one is, that the fish can compress as it pleases, to a certain extent, its bladder, or dilate it ; which we prove by the peculiar muscles with which the bladder is furnished in certain fishes, and by the mediate action which the sides and the muscles of the abdomen exercise on it in all those which have it.

M. Delaroche also adopts this second part of the common opinion.

He thinks even that it is in this way the fish supplies, when it rises, the pressure exercised on its bladder in deep water by the column of vater above it. Were it otherwise, 
the air, which would be no longer compressed, would be too much dilated, and would render the fish too light, or even produce some rupture, as happens to fishes drawn suddenly from great depths.

But who is there who is not aware, that this, on the part of nature, would be correcting very clumsily a defect which she might have refrained from introducing at all into her work? She had only to give no air bladder-at all to fishes; and we have seen that she need not have done so to place them in equilibrium with the water : in that case she would no longer have required the apparatus of compression, which has been supposed as serving only to correct the inconvenience of an useless bladder.

Thus we are of opinion that the third, and the chief part of the commonly received opinion, in reality resolves the problem : we mean that part of it which says, that the bladder is placed there to assist the fish in ascending and descending, according as it is compressed and dilated; and we confess that we do not see why $M$. Delaroche should reject this use of the bladder, to which the two others are, in our opinion, merely accessaries.

That the fish has strength sufficient to enable it to descend, clearly results from what $M$. Delaroche himself admits; for if the fish, which ascends 30 feet for example (and it is difficult not to believe that many fishes can ascend that height without any accident), if, we say, such $a$ fish has sufficient strength to compress its bladder, by means of its muscles, to the same degree that the 30 feet of water formerly did, it is evident that a similar fish, supposed to be in equilibrium at the height to which the former ascended, will also have sufficient strength to compress its bladder, as much as would the addition of a weight of $\mathbf{3 0}$ feet, and that there would result from such a compression or diminution of volume more than sufficient to force it to descend.

M. Delaroche, against this most essential part of the vulgar opinion, advances only a single objection, which be borrows from $M$. Fischer : this is, that the variation of speeific gravity which may result, with respect to the total body of fishes, from the variations of the volume of the bladder being very small, the ascents or descents, which are the consequence of it, could not but be very slow: but, besides, the circumstance of these variations never having been yet measured, no person has ever said that the bladder cannot be aided in this function by other organs. Those fishes which haye no bladder, ascend and descend, 
descend very well, altbough, other circumstances considered; ratherm ore tardily. Now those which have a bladder have, in addition, all the organs employed by those which have none, and they can use them like the others.

One difficulty which we have sometimes heard started, is to ask how a fish, when it wishes to ascend from the bottom of the sea, can find strength to raise up by means of its sides, or generally of its integuments, the enormous column of water which lies upon it, in order to permit its bladder to dilate. But as this vessel is already, by its compression, in equilibrium with the water which presses it, the least effort is sufficient; and even this effort, however small, is nevertheless necessary, that the fish may only rise a few feet by the means which are common to it with the fishes without bladder : instantly its bladder, being less compressed, will be too inuch dilated; and, according to M. Delaroche's own experiments, it will carry it precipitately upwards, and burst its entrails if it does not speedily close it. This second objection is refuted therefore like the former.

Thus we think we ought to adhere to the ideas of Borelli, as to the use of the air-vessel of fishes; but although we differ in opinion from $M$. Delaroche on this point, we do not the less regard his Memoir as worthy of approbation, from the great number of new and correct observations which it contains, as to the auatomical structure of the bladder, as well as upon the nature and sources of the air which it contains; and we have the honour to recommend that it should be printed among the Memoirs of Savans Elrangers. Signed,

Lacepede, Vauquelin, Cuvier.

L. Notices respecting New Books.

$M_{\mathrm{R}}$. Accù has just published a "Mamual of a Course of Lectures on Experimental Chemistry and on Mineralogy; containing, in the Form of Axioms and concise Outlines, the Elements and findanental Truths of chemical and mineralogical Scicnce : intended to illustrate the Lectures on these Branches of Knowledge in the Theatre of the Surry Institution; with an Account of the Action of chemical Tests and Modes of applying them in the Practice of the Science."

THe very full title of this little work (about 230 pages mall 12mo.) sufficiently explains its object. The author states that in writing it he has endeavoured to exhibit, to the learner, those "important facts and fundamental doctrines 